\title{
Calorific evaluation and energy potential of grape pomace
}

\author{
Patrik Burg' ${ }^{1 *}$, David Ludín', Kazimierz Rutkowski', Anna Krakowiak-Bal', Petr Trávníček ${ }^{3}$, \\ Pavel Zemánek ${ }^{1}$, Jan Turan ${ }^{4}$, and Vladimir Višacki ${ }^{4}$ \\ ${ }^{1}$ Department of Horticultural Machinery, Mendel University in Brno, Valtická 337, 69144 Lednice, Czech Republic \\ ${ }^{2}$ Department of Production and Power Engineering, University of Agriculture in Kraków, Al. Mickiewicza 21, \\ 31-120 Kraków, Poland \\ ${ }^{3}$ Department of Agricultural, Food and Environmental Engineering, Mendel University in Brno, Zemědělská 1, \\ 61300 Brno, Czech Republic \\ ${ }^{4}$ Department of Agricultural Engineering, University of Novi Sad, Trg Dositeja Obradovića 8, 21000 Novi Sad, Serbia
}

Received June 16, 2015; accepted February 24, 2016

\begin{abstract}
A b s t r a c t. This article deals with energetic evaluation and potential of pomace - a waste product originating during production of grape wine. Calorimetric analysis of 19 grapevine varieties was performed in 2013 and 2014. The aim was to specify their combustible limit and the gross calorific value. The evaluations were performed on pristine pomace, pomace without seeds, and only on seeds themselves. The results obtained imply that pomace is an interesting energetic resource with a gross calorific value of 16.07-18.97 $\mathrm{MJ} \mathrm{kg}^{-1}$. Lower calorific values were detected in pomace after seed separation ie $14.60-17.75 \mathrm{MJ} \mathrm{kg}^{-1}$; on the contrary, seeds alone had the highest calorific values of 19.78-21.13 MJ $\mathrm{kg}^{-1}$. It can be assumed from the results of energetic evaluation of pomace in Czech Republic conditions that, by purposeful and efficient usage of pomace, $6.4 \mathrm{GWh}$ of electric energy and $28 \mathrm{GWh}$ of thermal energy can be generated.

$\mathrm{K}$ e y w o r d s: grapevine production, pomace, calorific value, energetic potential
\end{abstract}

\section{INTRODUCTION}

The development of renewable energy sources has emerged as a desirable policy towards enhancing the fragile global energy system with its limited fossil fuel resources and diminishing related environmental problems (reducing greenhouse gas emissions).

In recent years, waste biomass has become a very important alternative in energy production. Its utilization includes a wide range of potential thermochemical, physicochemical, and bio-chemical processes. The use of biofuels has also its disadvantages, for example, high humidity, high costs, and complicated logistics during biomass transport (Hamelinck et al., 2005).

Renewable energy sources play a pivotal role in the current global strategies for reducing greenhouse gas emissions and partially in the endeavour to replace fossil fuels. Reserves of fossil fuels, such as oil, gas, and coal are the main sources of energy, spread over only a small number of countries, thus forming a fragile energy supply that is expected to reach its limit within the foreseeable future (Iakovou et al., 2010; Yamamoto et al., 2001).

Global warming has emerged as a critical issue for the international community. Developed countries had been required to reduce their greenhouse gas emissions below levels specified for each of them until 2012. At the same time, the European Commission has set mandatory targets for Member States of the European Union (EU) to reduce their greenhouse gas emissions honouring their commitments up to 2020. Furthermore, the EU has emerged as a global leader in limiting carbon dioxide emissions by establishing the European Union Emission Trading Scheme (EU ETS), the largest cross-national, emissions trading scheme in the world. The recently published Directive 2009/29/EC aims to further improve and extend the greenhouse gas emission allowance trading scheme of the community by further strengthening the incentives for the increased use of alternative energy sources (Allen et al., 1997; Iakovou et al., 2010). 
Conversion of waste biomass and organic substrates into energy includes a wide range of different types and sources of biomass, conversion options, end-use applications, and infrastructure requirements (Grassi and Bridgwater, 1990; Karagiannidis et al., 2009). Many of the processes are suitable for either the direct conversion of biomass or the conversion of intermediate types of biomass. Factors that influence the choice of a conversion process include the type and quantity of biomass feedstock and the desired form of the produced energy ie end-use requirements, environmental standards, economic conditions, and other project-specific factors (Hulteberg and Karlsson, 2009).

Biomass encompasses - among others - vegetation, energy crops, as well as biosolids, animal, forestry, and agricultural residues, the organic fraction of municipal waste, and certain types of different industrial wastes (Hoogwijk et $a l ., 2003)$. From the global point of view, grapevine pressings, a by-product of wine industry, is a significant source of biomass. Organisation Internetionale de la Vignet et du Vin (OIV, 2009) estimates that there are over 66.5 million $t$ of grapevines manufactured globally, with 38 million $\mathrm{t}$ in Europe. This means that only in European conditions approximately 8 million $t$ of pomace are produced.

Pomace consists of $8 \%$ of seeds, $10 \%$ of foot-stalks and fractions of the stem, $25 \%$ of skins of pressed grapes, and $57 \%$ of marrow berries (Burg et al., 2014). The amount and quality of produced pomace is influenced by various factors. Not only the species of wine, way of harvesting and manufacture, but also the chosen way of pressing can make a big difference (Bird, 2012; Hardie et al., 1996). Solving the important questions concerning this alternative energy source has frequently become a subject of discussion lately.

The aim of this article is to evaluate the energetic potential of grape pomace and its weight and energetic ratio in Czech Republic conditions.

\section{MATERIALS AND METHODS}

In 2013 and 2014, analysis of 19 pomace from different grapevines was performed repeatedly - Grüner Veltliner (GV), Pinot Blanc (PB), Hibernal (Hi), Merlot (Me), Pinot Gris (PG), Palava (Pa), Rheinriesling (RR), Welsch Riesling (WR), Tramin (Sa), Pinot noir (PN), Lemberger (LE), Neronet (Ne), Alibernet (Al), Zweigeltrebe ( $\mathrm{Zw})$, Andre (An), Laurot (La), Cabernet Moravia (CM), Chardonnay
(Ch), and Cabernet Sauvignon (CS). Pomace was supplied by winegrowing subjects in Bohemia (Mělník, Žernoseky) and Moravia (Znojmo, Velké Bílovice, Strážnice).

Evaluation of various species of pomace - pristine, without seeds, and only on seeds themselves - was made during the analysis. These variations were chosen specifically, because lately there has been an increasing demand for seed separation and their consecutive manufacturing (oils, extraction of biologically active substances), which yields a secondary product - seedless pomace (Jackson, 2008).

Evaluation of dry mass was made on all samples according to norm ČSN EN 14346:2007. Muffle furnace LMH 07/12 was used to assess dry mass. Elementary composition of grape pressings was assessed with elementary analysis of single samples with TOC/TN analyzer unit multi N/C 2100S, furnace HT 1300, and gas chromatograph Trace GC ultra.

For assessment of the gross heating value, a calorimeter Anton Parr MCR 102 was used, and for exact assessment of weight of the incinerated sample, we used an analytical scale Ohaus Adventurer Pro AV264C. The results of the gross heating values were in accordance with norm ČSN ISO 1928:1999 recalculated according to Eq. (1):

$$
Q^{r}{ }_{i}=Q^{r}{ }_{s}-\gamma\left(W_{t}^{r}+8.94 H_{t}^{r}\right),
$$

where: $Q_{s}^{r}$ - gross heating value of the original sample $\left(\mathrm{MJ} \mathrm{kg}^{-1}\right), \gamma$-ratio of evaporation of $1 \% \mathrm{H}_{2} \mathrm{O}\left(\mathrm{MJ} \mathrm{kg}^{-1}\right)$, at temperature $25^{\circ} \mathrm{C} ; \gamma=0.02442 \mathrm{MJ} \mathrm{kg}^{-1}, 8,94$ - hydrogen to water conversion ratio of $(-) W_{t}^{r}$ - total water content in the original sample (\%), $H_{t}^{r}$ - total hydrogen content in the original sample (\%).

Program STATISTICA CZ 12 (StatSoft) was used to evaluate evidence of the differences. The statistical methods used included ANOVA $(\alpha=0.05)$ and a multidimensional statistical method - Cluster analysis, which classifies samples into groups (clusters), so that samples belonging to the same group are more similar than the objects of the other groups.

\section{RESULTS AND DISCUSSION}

Table 1 shows the mean values of the elemental composition of the analysed pomace samples from white and blue grape vine varieties. The moisture of the analysed pomace samples after drying was in the range of $9.33-9.68 \%$.

T a b l e 1. Mean values of the elemental pomace composition

\begin{tabular}{lcccccc}
\hline & $\mathrm{C}$ & $\mathrm{H}$ & $\mathrm{O}$ & $\mathrm{N}$ & $\mathrm{S}$ & Ash \\
\cline { 2 - 7 } Variety & & & $(\%)$ & & & \\
\hline \multirow{2}{*}{ White } & 52.9 & 5.82 & 34.24 & 0.55 & 4.12 & 2.25 \\
Blue & 41.34 & 5.96 & 44.91 & 0.67 & 3.37 & 3.51 \\
\hline
\end{tabular}




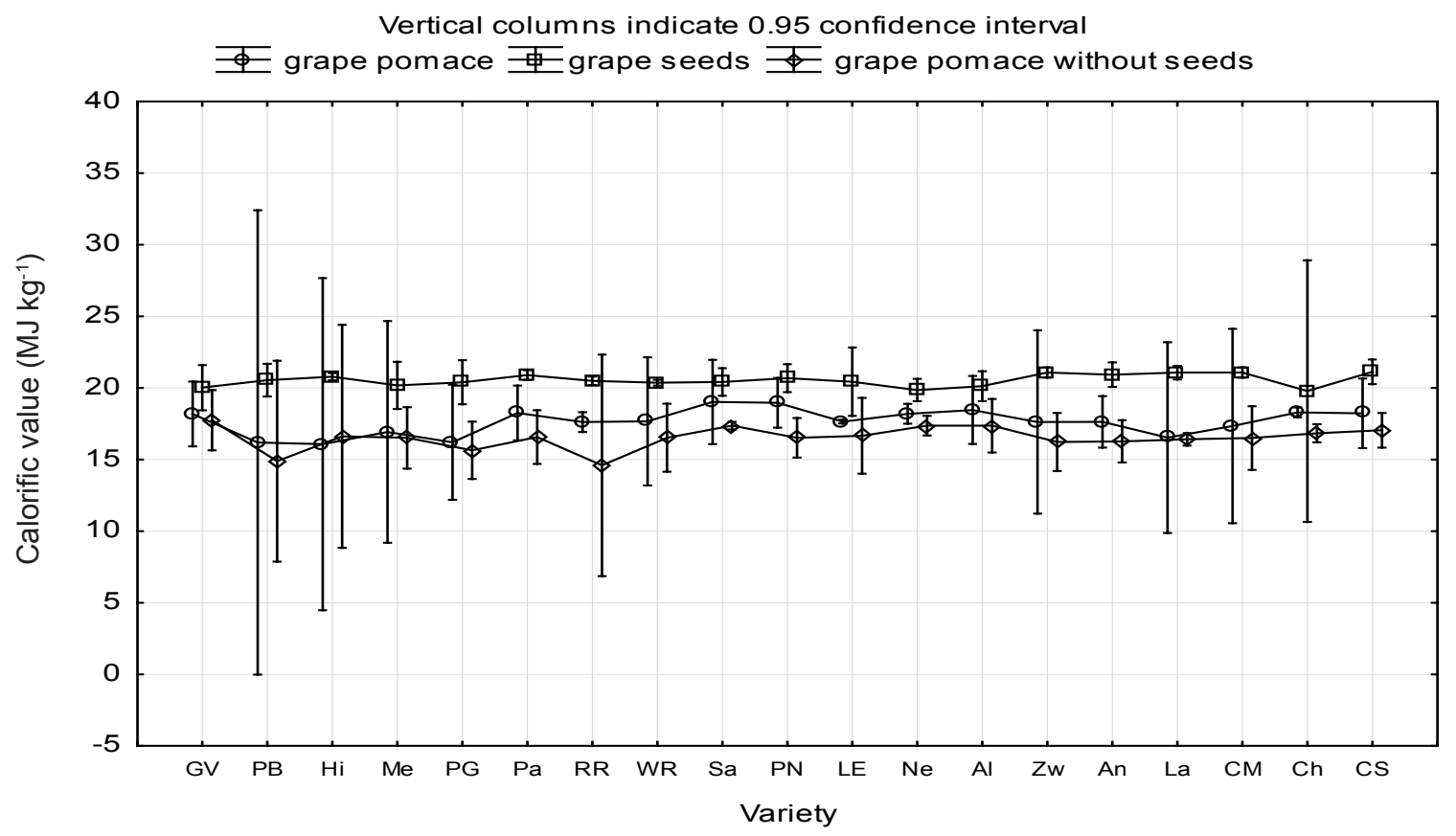

Fig. 1. Effect of variety on the calorific values of grape pomace.

The lowest calorific values were determined for the seedless pomace: $14.60-17.75 \mathrm{MJ} \mathrm{kg}^{-1}$. Pomace in original compositions reached a calorific value in the range of $16.07-$ $18.97 \mathrm{MJ} \mathrm{kg}^{-1}$. The highest calorific value was detected in seeds of the vine itself and the values varied between 19.78 and $21.13 \mathrm{MJ} \mathrm{kg}^{-1}$. The variety plays an important role in the differences in calorific values (Fig. 1), but in practice, the processing technology also has a significant role.

Annamalai et al. (1987) estimated the calorific value of pomace at $20.34 \mathrm{MJ} \mathrm{kg}^{-1}$. For example, McCormick and Kåberger (2007) and Freppaz et al. (2004) dealt with the issue of energy recovery in other alternative energy sources. The results of their work show that the calorific value of pellets from fast growing woody species ranges around $18.5 \mathrm{MJ} \mathrm{kg}^{-1}$, for pellets from plant biomass around $16 \mathrm{MJ}$ $\mathrm{kg}^{-1}$, for grain $18 \mathrm{MJ} \mathrm{kg}^{-1}$, and for forage cake $14.2 \mathrm{MJ} \mathrm{kg}^{-1}$. Walg (2007) and Souček and Burg (2010) evaluated the calorific value of the waste product from another vineyard production, which is derived from winter cuttings of cut vines with humidity below $10 \%$. The authors established calorific values for individual varieties between 14.39 and $16.66 \mathrm{MJ} \mathrm{kg}^{-1}$.

The lower calorific value of pomace after separation of seeds (14.60-17.75 $\mathrm{MJ} \mathrm{kg}^{-1}$ ) and the highest calorific value of seeds themselves $\left(19.78-21.13 \mathrm{MJ} \mathrm{kg}^{-1}\right)$ can be explained by the energy content of valuable components, eg the oil contained in the seeds. The oil content in the seeds of the vine and the content of bioactive compounds in whole grapes are specific varietal characteristics, which also depend on the environmental conditions (Pardo et al.,
2009). For varieties of vines commonly grown in the Czech Republic, this data is not yet available. According to literature, the proportion of oils in seeds varies between 5 and $20 \%$ of their dry weight (Ohnishi et al. (1990), Baydar et al. (2007), Tangolar et al. (2009)). In terms of practical application, however, we cannot assume the possibility of using vine seeds for energy purposes. Also Berndes et al. (2003) concludes that the calorific value of botanical raw materials can increase the content of energetic valuable components, such as resin or oil.

The cluster analysis results presented in Fig. 2 show that the pomace of Riesling, Pinot Blanc and Pinot Gris grape varieties exhibit lower calorific values. This corresponds with the results of monitoring the number of seeds in each berry conducted by Boselli et al. (1995) and Skala (2011). From 40 assorted varieties, most immature seeds were found in the Riesling and Pinot Gris varieties. For other varieties, the differences are not so significant.

The resulting calorific value suggests that in terms of energy utilization, pomace is an interesting material. When considering the practical use of grape pomace for energy purposes, it is necessary to specify the following steps - pomace collection from producers and delivery to incinerators, mechanical dehydration of pomace, pomace drying (using outlet heat), dried pomace final processing, storage, and dosing during incineration.

The findings were processed in a model diagram of the mass and energy balances for pomace from the Czech Republic, as suggested in Fig. 3. 


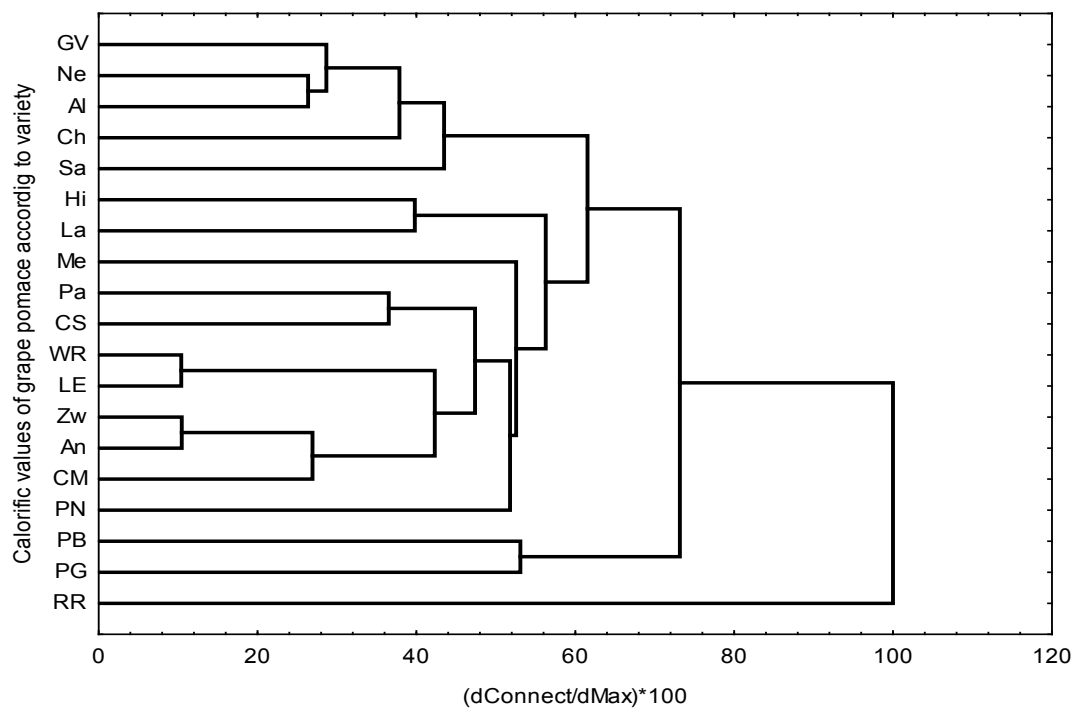

Fig. 2. Cluster analysis of calorific values.

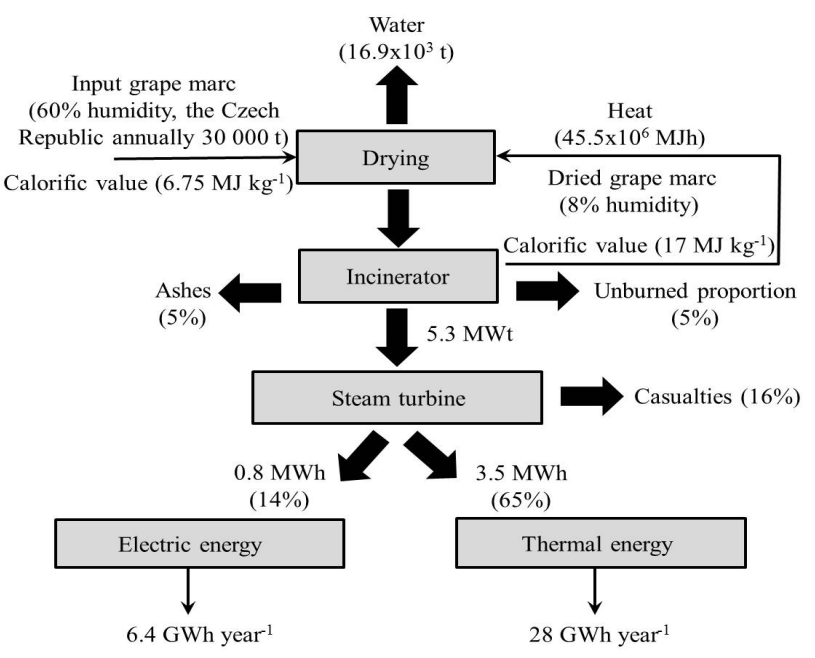

Fig. 3. Scheme of mass and energy balances for pomace in the Czech Republic.

\section{CONCLUSIONS}

1. Pomace represents an interesting energy source with a calorific value of 16.07-18.97 $\mathrm{MJ} \mathrm{kg}^{-1}$. Lower calorific values were determined in the pomace after separation of the seeds: $14.60-17.75 \mathrm{MJ} \mathrm{kg}^{-1}$, whereas the highest calorific values were determined in the seeds themselves ie 19.78-21.13 $\mathrm{MJ} \mathrm{kg}^{-1}$.

2. In practice, pomace may be considered for energy recovery as originally constituted pomace or without seeds, which represent a common waste material generated annually in the processing of grapes. The cluster analysis results indicate a lower calorific value of the pomace for the Riesling, Pinot Blanc, and Pinot Gris grape varieties. For pomace of the other varieties in the original composition, the differences were not as significant, as demonstrated by the ANOVA test.
3. When planning the use of grape pomace for energy purposes, there is also a need to resolve a range of the other problems associated with the concentration of plantations, deployment of processing facilities, logistical problems and storage capacity, humidity, and pomace processing, etc. The results of the energy balance of processed grape pomace in the Czech Republic shows that $6.4 \mathrm{GWh}$ year ${ }^{-1}$ of electric and $28 \mathrm{GWh}$ year $^{-1}$ of thermal energy can be gained annually.

\section{REFERENCES}

Allen J., Browne M., Hunter A., Boyd J., and Palmer H., 1998. Logistics management and costs of biomass fuel supply. Int. J. Phys. Distr. Log. Manag., 28, 463-477.

Annamalai K., Sweeten J.M., and Ramalingan S.C., 1987. Estimation of grossheating values of biomass fuels. Trans ASAE, 30, 4, 1205-1208.

Baydar N.G., Özkan G., and Çetin E.S., 2007. Characterization of grape seed and pomace oil extracts. Grasas Aceites, 58, 1, 29-33.

Berndes G., Hoogwijk M., and Van den Broek R., 2003. The contribution of biomass in the future global energy supply: a review of 17 studies. Biomass Bioenergy, 25(1), 1-28.

Bird D., 2012. Understanding wine technology. UK: DBQA Pulishing, Newarkl, UK.

Boselli M., Volpe B., and Di Vaio C., 1995. Effect of seed number per berry on mineral composition of grapevine (Vitis vinifera L.) berries. J. Hort. Sci., 70(3), 509-515.

Burg P., Dědina M., Hejtmánková A., Hejtmánková K., Jelínek A., Lachman J., Lipavský J., Mašán V., Pivec V., Skala O., Střalková R., Táborský J., and Zemánek P., 2014. Studies of biologically active substances in seeds and young wood grapevine and the possibilities of obtaining seed oils (in Czech). Folia Univ. agric. Silvic. Mendel. Brun. Monography. Brno: MENDELU in Brno, 7(7), 66-68.

ČSN EN 14346:2007. Characterization of waste - Calculation of dry matter and water content (in Czech). 
ČSN ISO 1928:1999. Solid fuels - Determination of gross calorific value by the calorimetric method in pressure vessel and calculate calorific value (in Czech).

Freppaz D., Minciardi R., Robba M., Rovatti M., Sacile R., and Taramasso A., 2004. Optimizing forest biomass exploitation for energy supply at a regional level. Biomass Bioenergy, 26(1), 15-25.

Grassi G. and Bridgwater A.V., 1990. Biomass for energy and environment, agriculture and industry in Europe - A strategy for the future Commission of the European Communities.

Hamelinck C.N., Suurs R.A.A., and Faaij A.P.C., 2005. International bioenergy transport costs and energy balance. Biomass Bioenergy, 29(2), 114-134.

Hardie W.J., O'Brien T.P., and Jaudzems V.G., 1996. Morphology, anatomy and development of the pericarp afteranthesis in grape Vitis vinifera L. Austral. J. Grape Wine, Res. 2, 97-142.

Hoogwijk M., Faaij A., Van den Broek R., Berndes G., Gielen D., and Turkenburg W., 2003. Exploration of the ranges of the global potential of biomass for energy. Biomass Bioenergy, 25(2), 119-133.

Hulteberg P.C. and Karlsson H.T., 2009. A study of combined biomass gasification andelectrolysis for hydrogen production. Int. J. Hydrogen Energy, 34, 772-782.

Iakovou E., Karagiannidis A., Vlachos D., Toka A., and Malamakis A., 2010. Waste biomass-to-energy supply chain management: a critical synthesis. Waste Manag., 30, $1860-1870$.

Jackson R.S., 2008. Wine science: principles and applications. Amsterdam: Elsevier/Academic Press, San Diego, USA.

Karagiannidis A., Wittmaier M., Langer S., Bilitewski B., and Malamakis A., 2009. Thermal processing of waste organic substrates: developing and applying anintegrated framework for feasibility assessment in developing countries. Renew. Sustain. Energy Rev., 13, 2156-2162.
McCormick K. and Kåberger T., 2007. Key barriers for bioenergy in Europe: economic conditions, know-how and institutional capacity, and supply chain co-ordination. Biomass Bioenergy, 31(7), 443-452.

Ohnishi M., Hirosh S., Kawaguchi M., Ito S., and Fujino Y., 1990. Chemical composition of lipids, especially triacyglycerol, in grape seeds. Agric. Biol. Chem., 54, 1035-1042.

Organisation Internetionale de la Vignet et du Vin (OIV), 2009. Internationaler Kodex der önologischen Praxis (in German). Bremen, Germany.

Pardo J.E., Fernandéz E., Rubio M., Alvarruiz A., and Alonso G.L., 2009. Characterization of grape seed oil from different grape varieties (Vitis vinifera) Eur. J. Lipid Sci. Technol., 111, 188-193.

Skala O., 2011. Research obtaining the biologically active substances (BAL) from grape seeds to improve the metabolism of farm animals as a basis for designing the best available techniques (bat) (in Czech). Periodic Message, 34, pages 15-21.

Souček J. and Burg P., 2010. Determination of calorific value of wood chips vine shoot from vines (in Czech). Acta Univ. agric. Silvic. Mendel. Brun., 58(1), 185-190.

Tangolar S.G., Ozogul Y., Tangolar S., and Torun A., 2009. Evaluation of fatty acid profiles and mineral content of grape seed oil of some grape genotypes. Int. J. Food Sci. Nutr., 60, 32-39.

Yamamoto H., Fujino J., and Yamaji K., 2001. Evaluation of bioenergy potential with a multi-regional global-land-useand-energy model. Biomass Bioenergy, 21(3), 185-203.

Walg O., 2007. Taschenbuch der Weinbautechnik (in German). Kaiserslautern: Rohr-Druck, Kaiserslautern, Germany. 